\title{
A call to halt destructive, illegal mining \\ in Zimbabwe
}

AUTHORS:

Mwazvita T.B. Dalu' ${ }^{1}$ iD

Ryan J. Wasserman² (iD Tatenda Dalu ${ }^{3}$

\section{AFFILIATIONS:}

${ }^{1}$ Environmental Science

Department, Rhodes University, Grahamstown, South Africa

${ }^{2}$ School of Science, Monash University Malaysia, Selangor Darul Ehsan, Malaysia

${ }^{3}$ Department of Zoology and Entomology, Rhodes University, Grahamstown, South Africa

\section{CORRESPONDENCE TO: Tatenda Dalu}

EMAIL:

dalutatenda@yahoo.co.uk

\section{KEYWORDS:}

artisanal mining; aquatic ecosystem vulnerability; biodiversity loss; ecosystem service loss; river degradation; sedimentation

\section{HOW TO CITE:}

Dalu MTB, Wasserman RJ, Dalu T. A call to halt destructive, illegal mining in Zimbabwe. S Afr J Sci. 2017:113(11/12), Art. \#a0242, 2 pages. http://dx.doi. org/10.17159/sajs.2017/a0242

(c) 2017. The Author(s). Published under a Creative Commons Attribution Licence.
Amidst the socio-economic meltdown in Zimbabwe, increased illegal mining activities on recently discovered diamond and gold deposits have given local people a source of livelihood. The problem of illegal gold mining is fast spreading through the Eastern Highlands and other parts of the country, as hundreds of artisanal gold miners swarm to the area, tearing up natural forests and plantations. Illegal mining operations are now rampant in the Chimanimani Mountains, a narrow belt located on the eastern Zimbabwean/western Mozambican border. The hilly and generally inaccessible nature of these mountains has preserved much of the native flora and fauna, including some endemic or near endemic animals and plants, ${ }^{1}$ and thus they are an important habitat. The highlands are also a crucial international catchment and a major water source for thousands of families dependent on agriculture and fishing for their livelihoods. However, with an estimated 400000 miners now operating illegally in Zimbabwe, ${ }^{2}$ the cumulative mining activities represent a major threat to people's livelihood security and to the integrity of this crucial catchment, habitat and associated river systems.

Classical artisanal mining in the region (banned in Zimbabwe since 2006) involved the excavation of river bottom sediment for the extraction of gold. River sediment was then processed for the separation of the precious heavy metal from non-target material. More recently, however, many small-scale artisanal activities have evolved into medium- and even large-scale operations, with new processes and/or techniques that involve diverting entire streams/rivers into larger areas holding alluvial gold deposit traces. This water is used to erode the off-stream sediment before being re-diverted into constructed streams which run through makeshift sorting stalls which trap gold. While the illegal artisanal mining engineering ingenuity is a marvel, its trade-off with the environment is unreasonably high. In many instances, harmful chemicals such as mercury and cyanide are also employed in the extraction process. ${ }^{3,4}$ We recorded mercury concentrations of $0.1-0.3 \mathrm{mg} / \mathrm{kg}$ in river sediment within the illegal mining areas, compared with $0 \mathrm{mg} / \mathrm{kg}$ mercury where there was no mining. However, there are far broader occupational safety and public health issues that deserve attention, and have resulted in this practice being considered high risk because of the many individuals who undertake it out of livelihood necessity. Smith et al. ${ }^{5}$ highlighted the challenges to mitigating health and safety risks among regulatory agencies that work with limited resources to meet the inspection requirements and concluded that research on health and safety issues in the artisanal mining sector must incorporate a regional and holistic approach with both quantitative and qualitative data collection methodologies. We observed that poor ventilation in tunnels and other risky mining practices by these illegal gold miners poses significant health and safety impacts to the miners. We speculate that the required air quantity in underground mining operations will be very low considering that the number of miners can be high, thus increasing the demand for airflow. Most of these miners do not wear protective clothing or equipment (e.g. dust masks), which poses significant risk for dust and chemical exposure for the miners. Further, the illegal miners work prolonged hours (sometimes $>24 \mathrm{~h}$ at a time), which means they are exposed to chemicals and dust for long periods. Nearby communities can also be exposed to dust and chemicals.

In addition to the damage that these artisanal mining practices impose upon personal health, safety and well-being, these practices also result in on-site river, riparian and terrestrial ecosystems' destruction through sediment and chemical pollution, along with severe and negative alterations to the rivers' banks and courses. Extensive riparian and other terrestrial vegetation removal has resulted in considerable soil loss through erosion. Near endemics such as the freshwater crab Potamonuates mutareensis and other aquatic organisms are seriously affected with no life being observed in affected sections of the river systems. ${ }^{1}$ Illegal gold diggers are washing away tonnes of soil into rivers at great loss to aquatic biodiversity. These activities are not only destroying vast portions of both terrestrial and aquatic ecosystems, but are also threatening the livelihood of thousands of villagers along the river valleys where these operations are concentrated. For example, the herbs that used to be collected from the river banks by rural communities, to prepare natural home-made remedies for mild ailments, are fast disappearing and/or no longer growing along the rivers because of heavy pollution by dangerous chemicals that the gold miners use, such as mercury and cyanide.

It is for these reasons that the Zimbabwean government urgently needs to revisit the monitoring and restrictions of artisanal mining. While the magnitude of the problem has not gone unnoticed by officials, the criminalisation of artisanal mining in $2006^{6}$ has largely failed to stop this poverty-driven activity. It is our view that the most pervasive and systematic threats to Zimbabwe's and the region's biodiversity as a whole are rooted in poor monitoring, management and legislation as institutional frameworks governing mining are normally sensitive only to formal mining operations and are blind to rapidly expanding illegal artisanal mining. ${ }^{7}$ An evaluation of the associated risks, an appraisal of mining laws and monitoring protocols as well as better enforcement of current laws are required for the adequate protection of the environment and local communities. Alternative forms of control should also be considered, such as the formalisation of more sustainable small-scale practices that conform to artisanal rather than fully commercial ventures. Formalisation of artisanal mining will also assist in achieving good governance, transparency of mineral production and trade while ensuring that social requirements are met and the environment is protected. We further suggest tightening the controls on mercury imports so that the country can meet its 2013 Minamata Convention on Mercury signatory commitment. Although the legalisation of artisanal mining can be considered a means to livelihood security for some, for many still depending on the natural terrestrial and aquatic systems, its monitoring and restrictions need to be better managed for all stakeholders to ensure a win-win scenario for the miners, environment, local communities and government. 


\section{Acknowledgements}

This study was funded by the Rufford Foundation (grant no. 21054-2 to T.D.). Any opinions, findings, conclusions or recommendations expressed in this material are those of the authors, and the Rufford Foundation does not accept any liability in this regard.

\section{References}

1. Dalu T, Sachikonye MT, Alexander ME, Dube T, Froneman WP, Manungo KI, et al. Ecological assessment of two species of potamonautid freshwater crabs from the eastern highlands of Zimbabwe, with implications for their conservation. PLoS ONE. 2016;11, e0145923, 17 pages. https://doi. org/10.1371/journal.pone.0145923

2. Metcalf SM, Veiga MM. Using street theatre to increase awareness of and reduce mercury pollution in the artisanal gold mining sector: A case from Zimbabwe. J Clean Prod. 2012;37:179-184. https://doi.org/10.1016/j. jclepro.2012.07.004
3. Hall SL. Talk of "clean coal" ignores dirty truth. Front Ecol Environ. 2009;7(2):70. https://doi.org/10.1890/09.WB.001

4. Saldarriaga-Isaza A, Villegas-Palacio C, Arango S. The public good dilemma of a non-renewable common resource: A look at the facts of artisanal gold mining. Resour Policy. 2013;38(2):224-232. https://doi.org/10.1016/j. resourpol.2013.02.001

5. Smith NM, Ali S, Bofinger C, Collins N. Human health and safety in artisanal and small-scale mining: An integrated approach to risk mitigation. J Clean Prod. 2016;129:43-52. https://doi.org/10.1016/j.jclepro.2016.04.124

6. Spiegel SJ. Shifting formalization policies and recentralizing power: The case of Zimbabwe's artisanal gold mining sector. Soc Nat Resour. 2015;28(5):543558. https://doi.org/10.1080/08941920.2015.1014606

7. Dube N, Moyo F, Sithole M, Ncube G, Nkala P, Tshuma N. Institutional exclusion and the tragedy of the commons: Artisanal mining in Matabeleland South Province, Zimbabwe. Extract Industr Soc. 2016;3(4):1084-1094. https://doi. org/10.1016/j.exis.2016.08.006 